\title{
Sastra anak: Genre realisme
}

\section{Miftakhuddin, Sukowati, Hidayah Mulayningsih S.}

Universitas Negeri Yogyakarta, Indonesia

\author{
A R T I C L E I N F O \\ Article history: \\ Received 01 Januari 2021 \\ Accepted 12 April 2021 \\ Available online 30 Juni \\ 2021 \\ Kata Kunci: \\ Sastra anak \\ Genre realisme \\ Cerita anak \\ Keywords: \\ Children literature \\ Realism \\ Children story
}

\begin{abstract}
A B S T R A K
Sastra dibebani dua tugas yang berbeda: sastra hendaknya melukiskan kenyataan selaras dengan kebenaran, tetapi sekaligus kenyataan itu ingin diubahnya. Gagasan realisme adalah sebuah doktrin sastra yang menegaskan bahwa tugas pengarang adalah menggambarkan realitas secara jujur dan historis (Eagleton, 1976). Prinsip realisme menghubungkan sastra dengan kebenaran historis. Dalam realisme, manusia, dengan pikiran dan perbuatannya mampu menentukan arah dari gerak sejarah. Realisme adalah teori sastra yang secara fundamental bertumpu pada sistem dialektika pengarang dengan lingkungan sosialnya. Segala tendensi sastra dipahami sebagai sebuah motif historis. Karya sastra selalu terhubung secara fundamental dengan lingkungan sosial pada masanya. Hakikat realisme ini bisa dikatakan menempatkan seni sebagai metode kontemplatif untuk mengangkat kesadaran ideologis sebagai manusia yang berkesadaran bahwa realitas sosial adalah sebuah ruang yang tidak dapat dihindari tetapi harus dikonstruksi.
\end{abstract}

\section{A B S T R A C T}

Literature is burdened with two different tasks: literature should describe reality in harmony with the truth, but at the same time it wants to change that reality. The idea of realism is a literary doctrine which asserts that the author's task is to describe reality honestly and historically (Eagleton, 1976). The principle of realism connects literature with historical truth. In realism, humans, with their thoughts and actions, are able to determine the direction of the movement of history. Realism is a literary theory that is fundamentally based on the dialectical system of the author and his social environment. All literary tendencies are understood as a historical motive. Literary works are always fundamentally connected with the social environment of their time. The essence of realism can be said to place art as a contemplative method to raise ideological awareness as a human being who is aware that social reality is a space that cannot be avoided but must be constructed.

Copyright $($ osf.io. All rights reserved.

\section{Pendahuluan}

Pembicaraan suatu genre akan berbeda dengan genre lainnya, tetapi juga sekaligus tumpang-tindih. Demikianlah menurut Nurgiyantoro (2016) dalam bukunya berjudul Sastra Anak. Ini disebabkan dalam tiap genre terdapat elemen tertentu yang kurang lebih sama. Artinya suatu bentuk cerita yang dikelompokkan ke dalam salah satu subgenre dalam sebuah genre, dapat memilki karakter yang dapat ditemukan dalam subgenre yang lain, tetapi dengan kriteria yang berbeda. Tumpang tindih dan saling silang dalam masalah genre ini sama persis dengan sifat komplenter dan substitusi dalam rumpun keilmuan dalam disiplin ilmu sosial, yang menurut penelilitan Miftakhuddin, Mustadi, Zulfiati (2019) sering menyebabkan kesalahpahaman dalam mendalami salah satu bidang studi. Demikianlah dalam memahami genre sastra anak, suatu karya sastra dapat diklasifikasikan ke dalam suatu genre, tetapi juga sekaligus dapat dikelompokkan ke dalam genre yang lain. 
Genre dapat dipahami sebagai macam atau tipe kesustraan yang memiliki seperangkat karakteristik umum (Lukens, 1999). Genre menunjuk pada pengelompokan kategori karya sastra menurut style, bentuk atau isi (Mitchell, 2003). Artinya, dalam menentukan masuk ke genre mana suatu sastra, ada pertimbangan berupa ciri khas sastra mengenai bentuk, gaya, dan isi atau kontennya. Misalnya, genre fiksi di dalamnya terdapat elemen struktural seperti alur, penokohan, latar, sudut pandang, dan lain-lain. Sedangkan genre puisi terdapat elemen struktural penting seperti rima, irama, diksi, imaji, dan lain-lain, yang pada prinsipnya elemenelemen struktural di antara kedua genre itu menunjukkan perbedaan dan eksistensi masingmasing.

Namun demikian, setiap genre sastra anak dapat berguna sebagai sarana menumbuh kembangkan dan melestarikan nilai-nilai dalam lingkungan sosial. Sebab, pewarisan nilai yang baik dan bertahan lama dalam memori dan diri seseorang ialah apabila dilakukan sejak masa kanak-kanak. Misalnya melalui pantun dan cerita yang pada mulanya dimaksudkan untuk menghibur dan menyenangkan anak, akan membangkitkan nilai keindahan dan merangsang anak untuk mempunyai apresiasi dan ekspresi seni (Puryanto, 2008). Bahkan menurut Zubaidah (2001), sastra bentuk puisi mempunyai kegunaan praktis untuk dipakai dalam evaluasi pembelajaran bahasa.

Sederhananya, karena sastra anak adalah sastra yang memang untuk konsumsi anakanak sesuai perkembangan emosional dan intelektualnya, maka harus mengandung unsur imajinatif, estetis, dan nilai moral yang bermanfaat untuk kehidupan anak. Unsur imajinatif dalam cerita (dongeng), misalnya, dapat membangkitkan khayalan anak untuk memposisikan diri menjadi salah satu tokoh dalam suatu cerita yang dia idolakan. Hal ini sangat sesuai dengan dunia anak yang penuh fantasi (Zubaidah, 2003). Karena unsur imajinatif yang lekat dalam dunia anak inilah kemudian anak bisa mengahayal dirinya menjadi seorang putri, pangeran, ataupun ksatria.

Oleh karena itu, sastra anak sebaiknya tetap berpegang pada realitas kehidupan, agar anak juga bisa merefleksikan apa yang terkandung dalam cerita ke dalam kehidupannya. Dalam kehidupan sosial anak, ada banyak peristiwa yang tidak selalu indah sebagaimana diilustrasikan dalam karya sastra pada umumnya. Anak bisa saja mengalami berbagai peristiwa tentang kematian, perceraian, kemiskinan, dan lain-lain (Miftakhuddin, 2018). Ini banyak terjadi pada kelompok masyarakat marginal yang bukan hanya secara ekonomi, melainkan juga secara sosial-kebudayaan (Miftakhuddin, 2019). Sesuai pandangan Nurgiyantoro (2016), bahwa sastra anak harus secara emosional psikologis dapat ditanggapi dan dipahami oleh anak yang berangkat dari fakta konkret yang dapat diimajinasikan. Pemahaman tersebut juga harus diperoleh anak melalui sudut pandangnya (Norton, 1983). Oleh sebab itu, perlu dipahami lebih dalam tentang genre sastra yang menggambarkan secara lebih konkret tentang kehidupan realistis bagi anak, yakni realisme.

\subsection{Rumusan masalah}

Rumusan masalah dalam paper ini ialah: (1) apa yang dimaksud genre realisme dalam sastra anak?, (2) apa saja sub-genre dalam genre realisme?, dan (3) seperti apa contoh karya sastra anak bergenre realisme?

\subsection{Tujuan penulisan}

Tujuan dilakukannya penulisan paper ini adalah: (1) mengetahui dan mmahami genre realisme dalam sastra anak, (2) mengetahui dan memahami sub-genre realisme, dan (3) memahami dan bisa membedakan berbagai contoh sastra bergenre realisme. 


\section{Hasil dan pembahasan}

Realisme dalam sastra dapat dipahami bahwa cerita yang dikisahkan itu mungkin saja ada dan benar-benar terjadi, walau tidak harus cerita itu benar-benar ada dan terjadi (Nurgiyantoro, 2016). Maksudnya, peristiwa dan jalinan peristiwa yang dikisahkan logis. Apa yang dituangkan dalam sastra genre ini merepresentasikan berbagai peristiwa, aksi dan reaksi, yang seolah-olah memang benar adanya, dan penyelesaiannya pun masuk akal serta dapat dipercaya. Secara keilmuan, cara berpikir yang demikian diperluan oleh semua individu (termasuk individu dalam masa perkembangan anak), sebab ini dapat mempertajam logika dan kepekaan terhadap realitas di masyarakat (Miftakhuddin, 2021). Namun demikian, Nurgiyantoro (2016) dalam bukunya berjudul Sastra Anak hanya terfokus pada jenis cerita, tidak menjelaskan tentang genre realisme untuk jenis lagu dan puisi. Menurutnya, ada empat jenis cerita yang dapat dikategorikan sebagai genre realisme, yangmana pembahasannya dapat tumpang-tindih. Keempatnya meliputi: cerita realistik, realisme binatang, realisme historis, dan cerita olahraga.

\section{Cerita Realisme}

Cerita realisme atau cerita realistic (realistic stories) biasanya bercerita tentang masalahmasalah sosial dengan menampilkan tokoh utama protagonis sebagai pelaku cerita. Masalahmasalah yang dihadapi tokoh itulah yang menjadi sumber pengembangan konflik dan alur cerita. Konflik yang dikisahkan dapat berkaitan dengan masalah sendiri, orang lain, atau sosial, dan bersifat realistik sebagaimana ditemukan dalam kehidupan sehari-hari (Nurgiyantoro, 2016).

Masih menurut Nurgiyantoro (2016), kaitan antara tokoh, konflik, alur, dan tema harus terjalin dengan baik dan saling berhubungan. Penyelesaian cerita tidak harus simplisistik dan sentimental dan kurang realistic dan adil. Dalam kehidupan sesungguhnya masalah tidak mudah diselesaikan dan bahkan mungkin tidak terselesaikan. Untuk cerita anak, cerita lebih banyak diselesaikan, tetapi harus tetap mempertahankan logika cerita. Pembaca anak yang mengidentifikasikan dirinya dengan tokoh protagonist akan menemukan penyelesaian yang belum tentu sesuai dengan harapannya. Cerita realistik dapat pembaca anak, kita untuk lebih memahami diri sendiri, orang lain lewat pengembangan cerita, tokoh dan konflik yang dapat dipercaya. Di bawah ini adalah beberapa contoh cerita realisme.
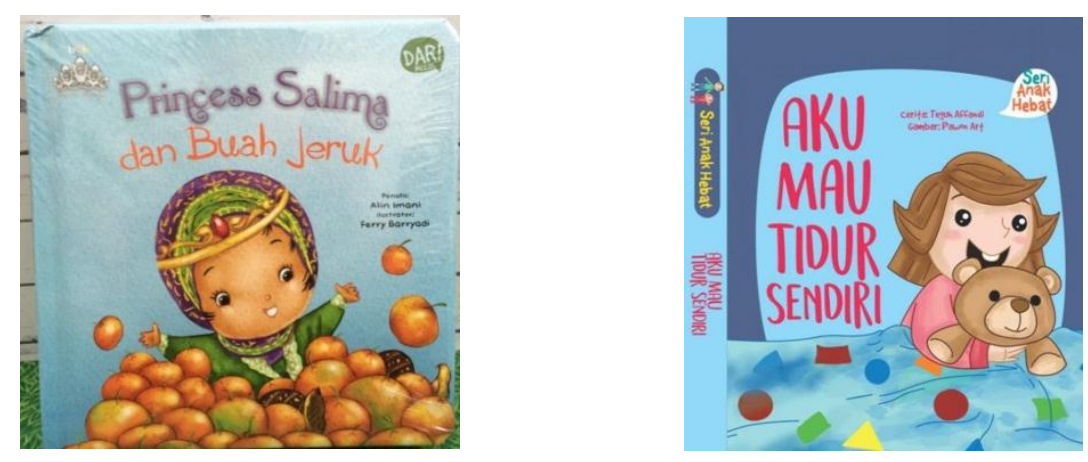

Dalam salah satu contoh yang berjudul "Princess Salima dan Buah Jeruk", diceritakan tentang Princess Salima yang tinggal di Istana yang terdapat di Negeri Basyira. Dicerirakan Princess Salima senang merangkai bunga di dekat jendela. Di jendela, dia suka melihat Nina yang sedang memetik buah jeruk di belakang istana. Nina adalah anak Paman Uki, seorang tukang 
kebun istana. Nina suka bersembunyi jika Princess Salima menghampirinya. "Jangan dekati aku, Princess aku bau jeruk". Kata Nina.

Esoknya, Princess Salima merangkai bunga dengan cepat. "Aha!". Tiba-tiba, dia punya ide yang hebat! Princess Salima mengambil daun dan buah jeruk, lalu menempelkannya ke tubuhnya. Tiba-tiba Princess salima berlari memeluk Nina di kebun jeruk. "Nina, aku sudah bau jeruk!” teriak Princess Salima. Ternyata Princess Salima ingin berteman dengan Nina. Setelah itu, mereka selalu bermain bersama di Istana.

Dari cerita diatas, dapat disimpulkan bahwa kita tidak boleh membeda-bedakan teman dalam berkawan dan selalu berbuat baik kepada semua orang. Dalam cerita tersebut, cocok digunakan pembaca anak-anak kelas rendah karena alur cerita dan konflik yang digambarkan, sangat sederhana, tidak kompleks, dan tokoh-tokohnya tidak lebih dari 10 orang. Penyelesaian cerita juga disuguhkan dengan menarik oleh penulis yang membuat anak-anak untuk menyelesaikannya hingga akhir cerita.

\section{Realisme Binatang}

Nurgiyantoro (2016) menjelaskan bahwa cerita realisme binatang (animal realism) adalah cerita tentang binatang yang bersifat nonfiksi. Lebih lanjut, Lukens (1999) menjelaskan bahwa realisme binatang merupakan jenis cerita yang sangat populer dalam dunia anak yang membahas binatang secara nyata. Sehingga tidak ada drama dalam cerita realisme binatang. Realisme binatang membahas secara nyata binatang yang hidup dilingkungan sekitar maupun dilingkungan yang berbeda. Anak-anak akan dapat mendapatkan pengatahuan tentang kehidupan binatang melalui cerita realisme binatang.

Cerita realisme adalah cerita tentang binatang, berbicara tentang binatang, mislanya yang berkaitan dengan bentuk fisik, habitat, cara dan siklus hidup, dan lain-lain. Cerita tersebut berwujud deskripsi tentang binatang yang tidak mengandung unsur personifikasi, binatang sebagaimana binatang yang tidak dapat berpikir seperti manusia. Menurut Mitchell (2003), hampir setiap anak memiliki pengalaman positif dengan hewan dan mereka sennag membaca yang didalamnya terdapat cerita tentang hewan. Dalam cerita binatang (yang dikenal dengan sebutan fabel) biasanya ditambahkan dimensi lain yang memunculkan konflik dalam cerita. Cerita realisme menampilkan cerita binatang yang dapat berbicara, berpikir, dan berkonflik sebagaimana halnya manusia karena cerita itu memang hadir sebagai personifikasi karakter manusia. Dengan demikian, cerita binatang menjadi tidak realistik, dan sulit diterima secara akal.

Oleh karena itu, cerita binatang tidak dikategorikan sebagai realisme binatang. Namun, cerita realisme binatang dapat juga ditulis dengan lebih menarik, dan karenanya menawarkan efek keindahan juga. Misalnya, cerita tentang penjelajahan dan penemuan kebiasaan hidup, cara bertahan hidup, cara bergaul dengan sesamanya, dan lain-lain yang realistik tentang kehidupan binatang, baik binatang yang jinak dan familiar maupun (apalagi) yang buas dan langka seperti film Planet Satwa, Killer Instinc, Wild Africa, Big Cat Diary, dan lain-lain yang dapat disaksikan lewat tayangan beberapa televisi swasta yang ternyata juga memukau. Lewat film tentang kehidupan binatang tersebut, umumnya terhadap binatang yang langka ditemui dalam kehidupan sehari-hari, dapat diperoleh pengetahuan dan pemahaman yang lebih tentang peri kebinatangan.

Realisme binatang dan fabel, keduanya merupakan jenis sastra yang berbeda. Oleh karena itu perlu dipahami betul karakteristik keduanya agar tidak terjadi kesalahan dalam penyusunannya. Fabel merupakan cerita binatang yang yang dimasukkan sebagai personifikasi karakter manusia. Fabel merupakan jenis sastra yang bersifat fiksi. Binatang-binatang tersebut 
dijadikan tokoh yang dapat bercerita dan berperilaku seperti manusia (Nurgiyantoro, 2016). Dalam cerita fabel mengandung pesan moral yang biasanya terdapat pada bagian akhir cerita. Tujuan dari pemilihan tokoh binatang dalam fabel adalah untuk mengkonkretkan ajaran dalam bentuk tingkah laku dan untuk menyamarkan ajaran melalui personifikasi binatang agar pesan moral yang terdapat dalam fabel tidak menyindir pembaca.

Sedangkan realisme binantang, menurut Nurgiyantoro (2016), merupakan cerita tentang binatang yang bersifat nonfiksi. Realisme binatang berisi fakta-fakta atau deskripsi tentang binatang. Misalnya yang berkaitan tentang bentuk fisik, habitat, siklus hidup, dan lain-lain. Tujuan dari realisme binatang adalah agar anak memperoleh pengetahuan dan pemahaman tentang binatang. Dibawah ini adalah contoh cerita realisme binatang kucing, lumba-lumba, dan gajah.

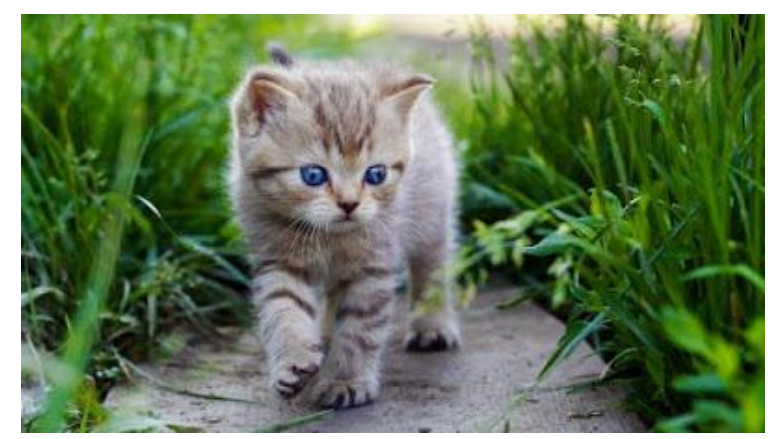

Kucing adalah sejenis mamalia karnivora dari keluarga Felidae. Kucing yang memiliki nama latin Felis silvestris catus. Kucing hanya memakan daging dan biasanya daging buruan segar. Kucing biasanya memiliki berat badan antara 2,5 hingga 7 kilogram dan jarang melebihi $10 \mathrm{~kg}$. Bila diberi makan berlebihan, kucing dapat mencapai berat badan $23 \mathrm{~kg}$. Habitat kucing adalah perumahan, pedesaan, dan perkotaan. Kucing dapat melompat, berlari, dan berjalan. Kucing memiliki kaki empat dan pada kakinya mempunyai kukuyang tajam diselimuti bulu. Kucing memiliki banyak warna dan macam pola. Ciri fisik ini tidak bergantung pada rasnya. Mata kucing jika dilihat pada malam hari seperti bersinar. Kucing menyimpan energi dengan cara tidur lebih sering ketimbang hewan lain. Lama tidur kucing bervariasi antara 12-16 jam per hari, dengan angka rata-rata 13-14 jam. Tetapi tidak jarang dijumpai kucing yang tidur selama 20 jam dalam satu hari. Masa kehamilan atau gestasi pada kucing berkisar 63 hari. Anak kucing terlahir buta dan tuli. Mata mereka baru terbuka pada usia 8-10 hari. Anak kucing akan disapih oleh induknya pada usia 6-7 minggu dan kematangan seksual dicapai pada umur 10-15 bulan. Kucing dapat mengandung 4 janin sekaligus karena rahimnya memiliki bentuk yang khusus dengan 4 bagian yang berbeda.

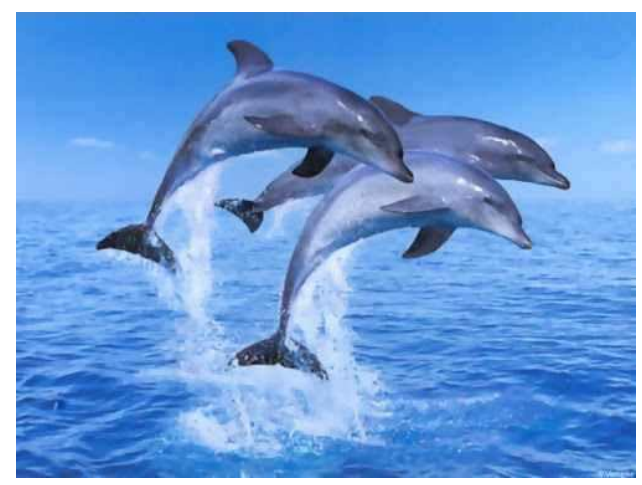


Lumba-lumba adalah mamalia laut. Mereka hidup di dalam air, tetapi harus naik juga ke permukaan air untuk bernafas. Lumba-lumba memiliki tubuh ramping yang membuatnya mampu berenang dengan cepat. Sirip ekor, yang disebut fluke, digunakan sebagai penggerak, sementara sirip lainnya yang terletak dibagian samping tubuhnya digunakan bersama-sama dengan seluruh bagian ekornya sebagai alat kontrol. Sirip punggung yang terletak dibagian atas tubuhnya berfungsi sebagai stabilisator pada saat lumba-lumba berenang. Warna dasar tubuh ikan lumba-lumba pada umumnya adalah abu-abu dan warna dibagian bawah tubuhnya lebih terang dari pada bagian atas dan sering terdapat garis dan petak-petak warna yang berbeda dan kontras. Tidak seperti kebanyakan mamalia, lumba-lumba tidak memiliki rambut. Makanan utama lumba-lumba adalah ikan tetapi saat mereka berada diwilayah yang jarang terdapat ikan mereka biasanya berburu cumi-cumi dan gurita. Lumba-lumba menelan makanan mereka tanpa dikunyah terlebih dahulu, mereka menggunakan otot-otot yang terdapat dibagian belakang lidahnya dan juga tenggorokannya untuk memeras air laut yang ikut terbawa pada saat mereka menelan makanannya.

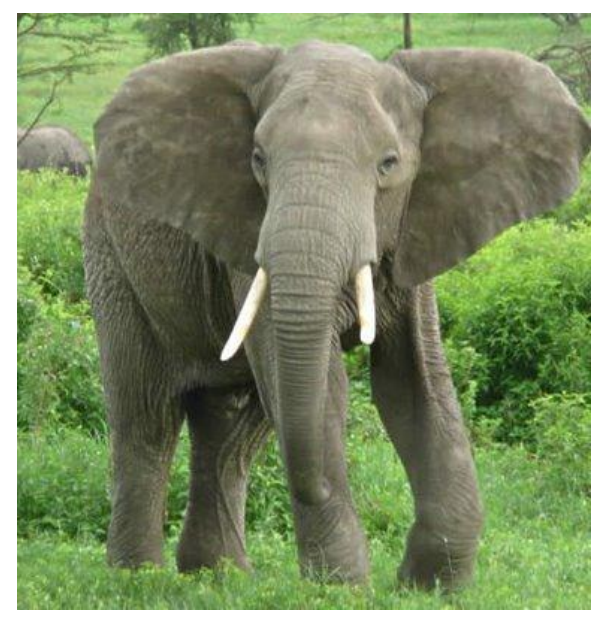

Gajah merupakan hewan herbivora yang dapat ditemui di berbagai habitat, seperti sabana, hutan, gurun, dan rawa-rawa. Mereka cenderung berada di dekat air. Gajah termasuk dalam kategori hewan herbivora. Ia menghabiskan 16 jam sehari untuk mengumpulkan makanan. Makanannya terdiri atas sedikitnya 50\% rumput, ditambah dengan dedaunan, ranting, akar, dan sedikit buah, benih dan bunga. Karena gajah hanya mencerna $40 \%$ dari yang dimakannya, mereka harus mengonsumsi makanan dalam jumlah besar. Gajah dewasa dapat mengonsumsi 300 hingga 600 pon (140-270 kg) makanan per hari. Enam puluh persen dari makanan tersebut tertinggal dalam perut gajah dan tidak dicerna. Tinggi dari gajah afrika dapat menacapai kurang lebih 3 sampai 4 meter dan massa berkisar antara 4,000 sampai 7,000 kilogram, sedangkan tinggi gajah asia berkisar antara 2 sampai 3.5 meter dan massanya berkisar antara 3,000 sampai 5,000 kilogram. Gajah menggunakan belalainya untuk untuk meletakkan makanan dan air ke dalam mulutnya, untuk mengangkat benda-benda, dan, tentunya, untuk mencium bebauan. Belalai ini mampu membawa empat liter air. Mereka dapat menghisap air ini kedalam mulut dan meminumnya atau menyiramkannya ke tubuh mereka. Selain itu, gajah menggunakan belalainya untuk menyiram air ke badannya untuk mandi atau menyemprotkan debu pada badannya untuk mandi debu. Pada kedua sisi mulutnya, gajah memiliki dua gading yang runcing. Gading ini membantu mereka menjaga diri. Selain itu, seekor gajah menggunakan salah satu gadingnya untuk menggali tanah dan mencari air.

Disamping cerita realisme binatang sebagaimana ditampilkan di atas, cerita realisme dapat pula dikemas ke dalam bentuk buku seperti buku-buku di bawah ini. 

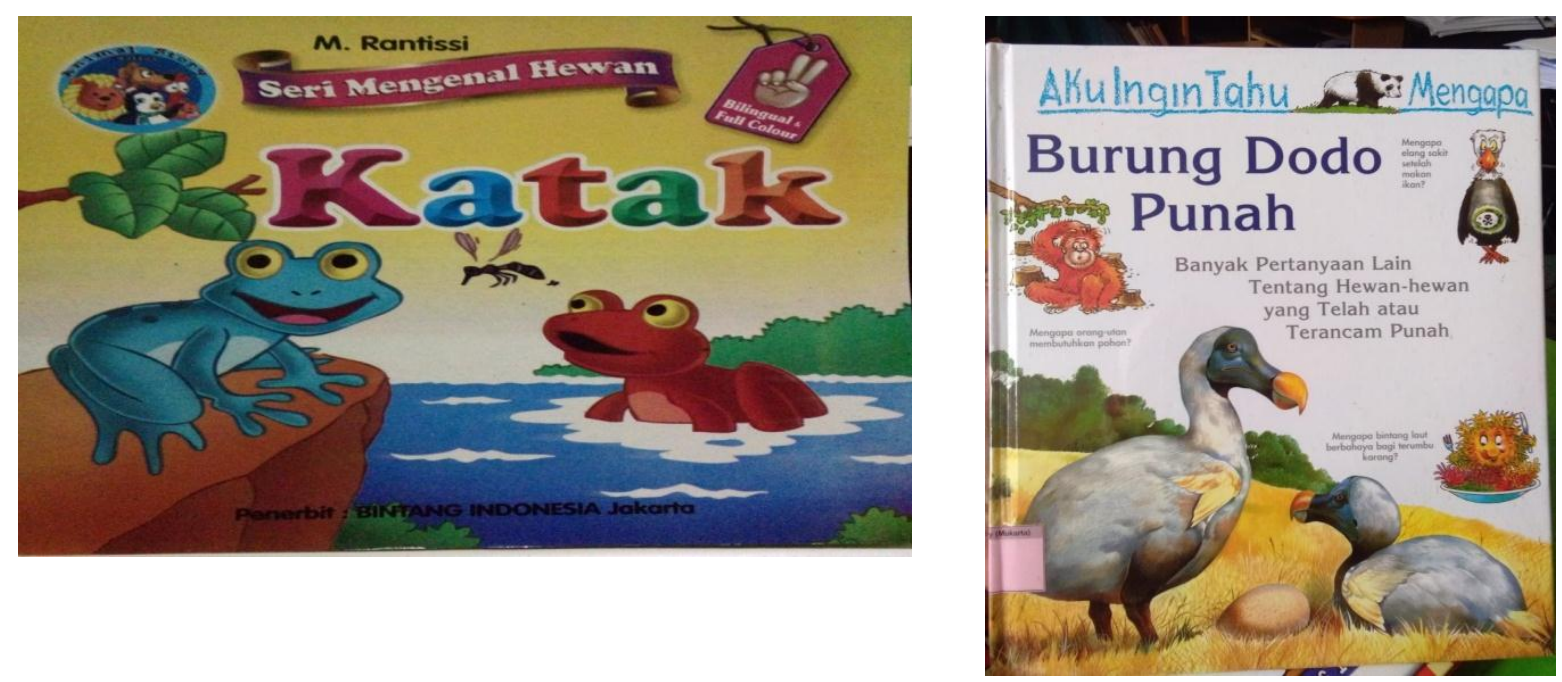

\section{Realisme Historis}

Sesuai dengan namanya, realisme historis menceritakan peristiwa masa lampau sesuai dengan kaidah berpikir logis atau masuk akal. Realisme historis biasanya merujuk kepada sejarah-sejarah populer, meski apa yang biasanya dikisahkan dalam sejarah belum tentu valid karena penulis sejarah kadang-kadang mempunyai kepentingan dan ketertarikan tertentu (Miftakhuddin, 2020). Bahkan dalam kasus-kasus tertentu, karya sejarah juga kerap disisipi unsur-unsur mitologis (Murwonugroho \& Miftakhuddin, 2020). Namun concern dari sastra anak genre realisme bukan pada validitas isi, melainkan pada rasionalitas jalan cerita, tokoh, waktu, dan tempat peristiwa yang dikisahkan. Otomatis, setting cerita harus mengambil masa lampau sebagai platform penulisan ceritanya. Menurut Nurgiyantoro (2016), setting itu harus melingkupi deskripsi lengkap dari masa lampau seperti: kondisi lingkungan alam, cara berpakaian tokoh, transportasi, persenjataan dan lain-lain. Cerita realisme biasanya mengambil satu atau beberapa tokoh yang digunakan sebagai acuan dalam pengembangan alur (Nurgiyantoro, 2004). Contoh cerita realisme historis misalnya Perang Diponegoro, Masa Kecil Soekarno, Kapitan Pattimura, dan cerita lain yang memang mempunyai fakta kesejarahan.

Namun demikian, sebagaimana konsep dasar sastra realisme menurut Nurgiyantoro (2016), realisme historis dapat dikembangkan menjadi fiksik historis, asalkan logis dan pemecahan masalahnya juga masuk akal. Fiksi historis memang mengandung unsur imajinasi, tapi harus dipadukan juga secara integral dengan fakta. Fiksi historis sebagai genre realisme, dalam batas-batas tertentu tidak boleh terlalu menyimpang dengan memasukkan unsur legenda, mitos, dan tokoh-tokoh fiktif. Karena bagaimanapun juga, realisme historis pada hakekatnya adalah sejarah, yang dikemas dengan memperhatikan keindahan dan bahasa penuturan yang dipakai (Nurgiyantoro, 2004). Kisah Ken Arok dari Singosari, juga Gadjah Mada dari Majapahit merupakan cerita nyata yang kemudian menjadi cerita anak realisme historis ketika bahasa dan penuturannya dikemas secara sederhana, lazim, dan sesuai tahap perkembangan anak. Akan lebih baik lagi jika dalam penyajiannya disertai gambar-gambar. Berikut adalah contoh cerita historis yang cocok untuk anak. 

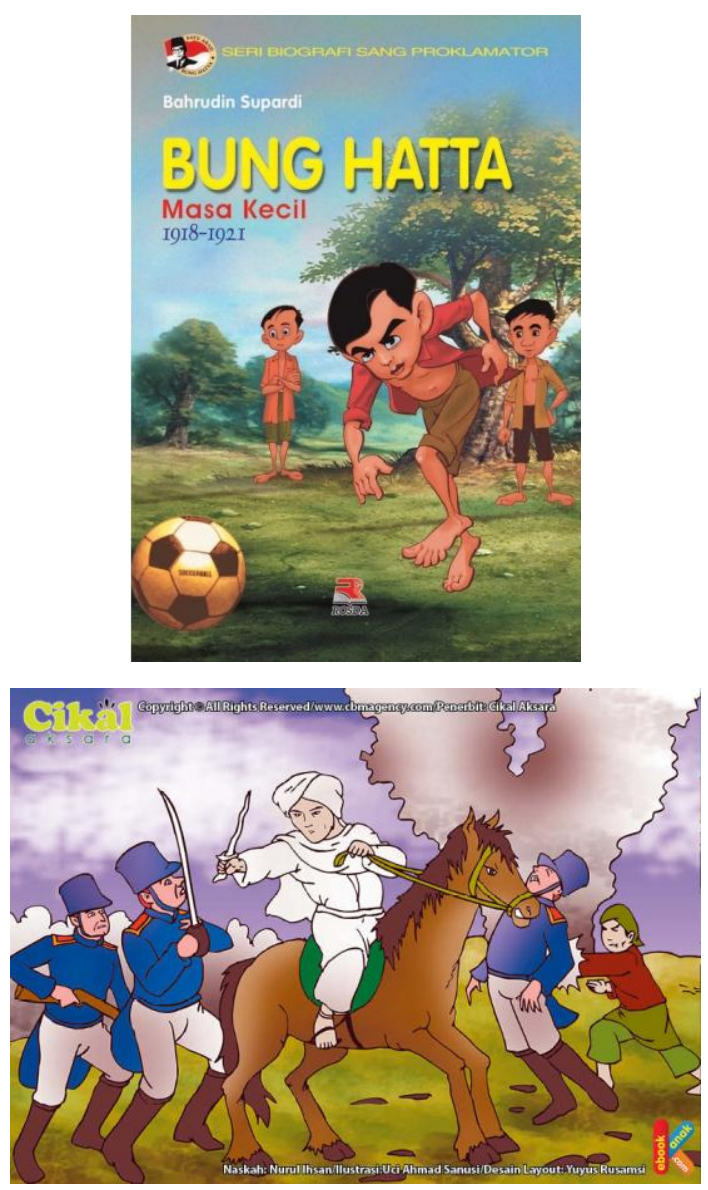
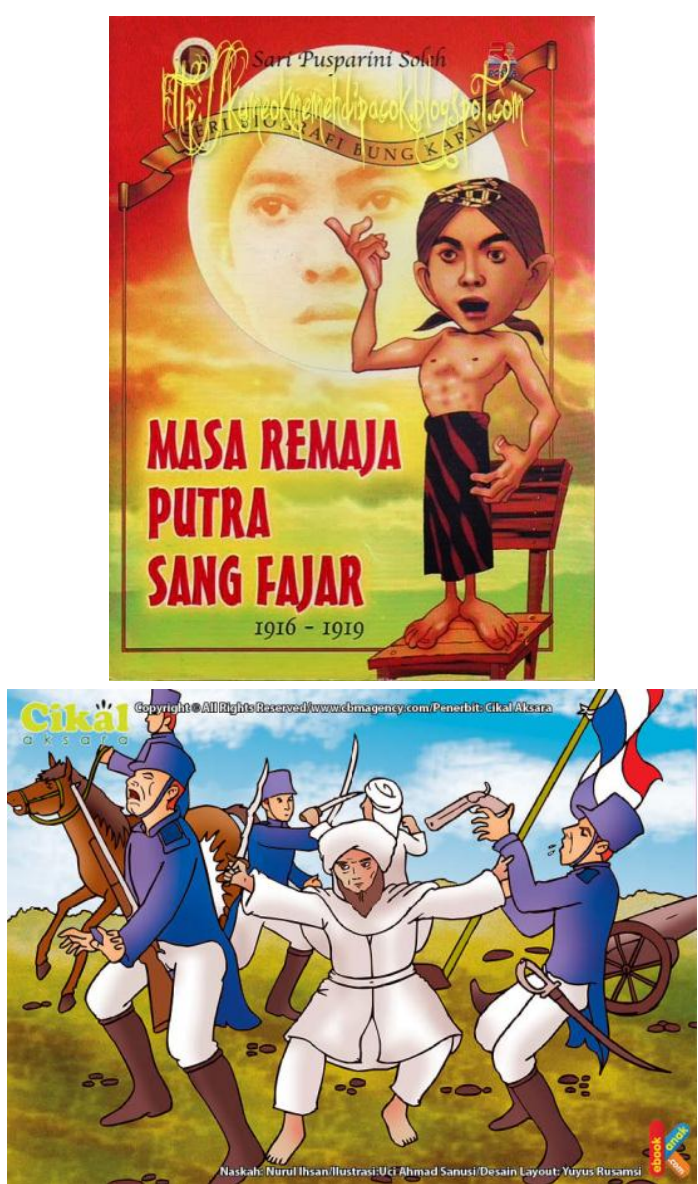

\section{Realisme Olahraga}

Realisme olahraga (sport stories) adalah cerita yang mengisahkan berbagai hal seputar aktivitas jasmani (keolahragaan). Sehingga cerita ini dapat berkaitan dengan berbagai macam olahraga dan atlet olahraga. Menurut Nurgiyantoro (2016), realisme olahraga dapat berkaitan dengan, dan dipakai dalam penanaman karakter fair play, kejujuran, kedisplinan, sportivitas, dan karakter lain yang berguna untuk pengembangan diri. Jika cerita olahraga ini dikemas dengan baik dan menarik, realisme olahraga tidak kalah memikat dibandingkan dengan jenis cerita lain. Terlebih lagi, banyak anak mengidolakan olahragawan terkenal. Berikut contohcontoh cerita realisme olahraga.
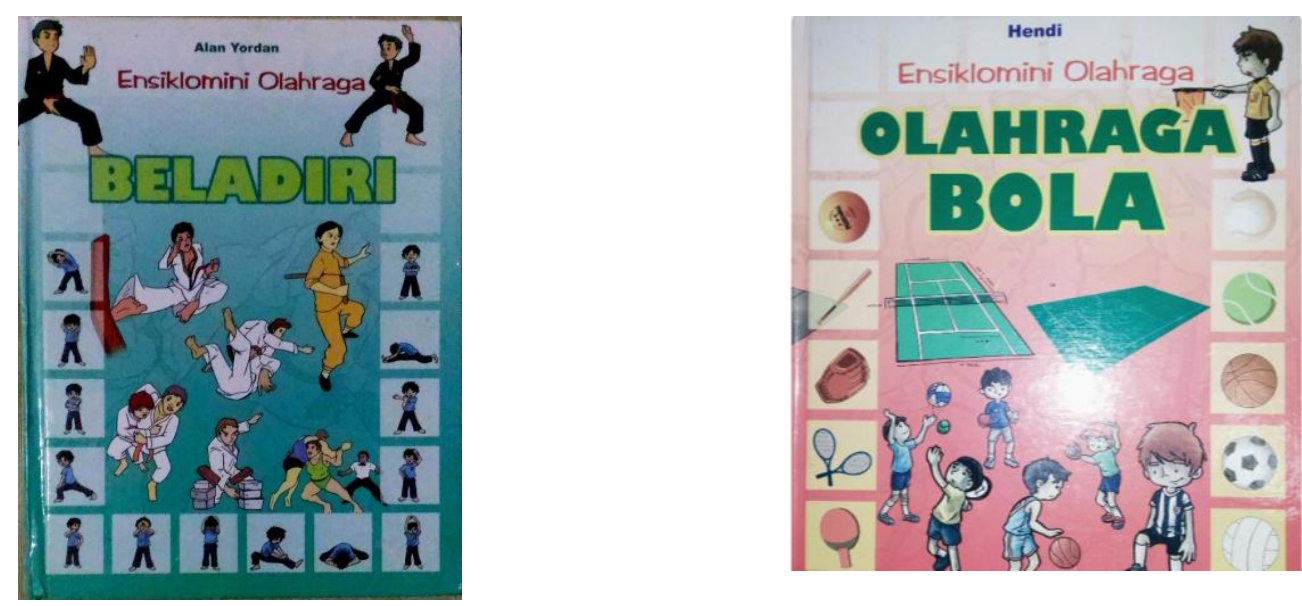


\section{Simpulan dan saran}

Menurut Lenin (dalam Luxemburg, Bal, \& Westseijen, 1989), realisme menuntut para pengarang agar melukiskan kenyataan dalam perkembangan revolusionernya, selaras dengan kebenaran dan fakta sejarah. Demikianlah sastra dibebani dua tugas yang berbeda: sastra hendaknya melukiskan kenyataan selaras dengan kebenaran, tetapi sekaligus kenyataan itu ingin diubahnya. Gagasan realisme adalah sebuah doktrin sastra yang menegaskan bahwa tugas pengarang adalah menggambarkan realitas secara jujur dan historis (Eagleton, 1976). Prinsip realisme menghubungkan sastra dengan kebenaran historis. Dalam realisme, manusia, dengan pikiran dan perbuatannya mampu menentukan arah dari gerak sejarah.

Realisme adalah teori sastra yang secara fundamental bertumpu pada sistem dialektika pengarang dengan lingkungan sosialnya. Segala tendensi sastra dipahami sebagai sebuah motif historis. Karya sastra selalu terhubung secara fundamental dengan lingkungan sosial pada masanya. Hakikat realisme ini bisa dikatakan menempatkan seni sebagai metode kontemplatif untuk mengangkat kesadaran ideologis sebagai manusia yang berkesadaran bahwa realitas sosial adalah sebuah ruang yang tidak dapat dihindari tetapi harus dikonstruksi (Maulina, 2013)

\section{References}

Eagleton, T. (1976). Marxism and Literary Criticism. California: University of California.

Lukens, R. J. (1999). A Critical Handbook of Children's Literature. New York: Longman.

Luxemburg, J. Van, Bal, M., \& Westseijen, W. G. (1989). Pengantar ilmu sastra (Terj. Dick Hartoko). Jakarta: Gramedia.

Maulina, Y. (2013). Realisme Dalam Cerita Pendek "Bulan Gendut Di Tepi Gangsal” Karya Wa Ode Wulan Ratna. Madah, 4(1).

Miftakhuddin, M. (2018). Kecenderungan Putus Sekolah Difabel Usia Pendidikan Dasar di Jember. INKLUSI Journal of Disability Studies, 5(1), 95-114.

Miftakhuddin, M. (2019). Dedication of Unej Mengajar to Improve the Human Resources' Quality in the Retarded Areas of Jember through a Participatory Approach. Proceeding of Community Development, 2, 454-466.

Miftakhuddin, A. M., \& Zulfiati, H. M. (2019). Misconceptions between Social Studies and Social Sciences among Pre-Service Elementary Teachers. International Journal of Education, 12(1), 16-25.

Miftakhuddin, M. (2020). Kolonialisme: Eksploitasi dan pembangunan menuju hegemoni. Jejak Publisher.

Miftakhuddin, M. (2021). Pendekatan penelitian pendidikan: Tinjauan dari perspektif filsafat ilmu.

Mitchell, D. (2003). Children's Literature, an Invitation to the World. Boston: Ablongman. 
Murwonugroho, W., \& Miftakhudin, M. (2020). Kajian Rupabheda: Tokoh-Tokoh Sri Tanjung pada Relief Candi Penataran. Panggung, 30(2).

Norton, D. E. (1983). Through the Eyes of a Child: An Introduction to Children's Literature. Ohio: Bell \& Howell Company.

Nurgiyantoro, B. (2004). Sastra Anak: Persoalan Genre. Humaniora, 16(2), 107-122. https://doi.org/10.22146/jh.v16i2.811

Nurgiyantoro, B. (2016). Sastra anak, pengantar pemahaman dunia anak. Yogyakarta: Gadjah Mada University Press.

Puryanto, E. (2008). Konsumsi anak dalam teks sastra di sekolah. In Makalah konferensi internasional kesusastraan XIX Hiski. Malang.

Zubaidah, E. (2001). Pemanfaatan sastra anak-anak dalam evaluasi pembelajaran bahasa Indonesia di Sekolah Dasar. Jurnal Ilmiah Guru “COPE," 5(2), 1-7.

Zubaidah, E. (2003). Penulisan sastra anak. Cakrawala Pendidikan, 22(1), 65-86. 